\title{
Automatic Gate with Track Switching
}

\author{
Mohd. Danish ${ }^{1}$, Prashant Kr. Singh ${ }^{2}$, Mrigank Shekhar ${ }^{3}$, Mrs. S.U Kulkarni ${ }^{4}$ \\ Bharati Vidyapeeth Deemed University, College of Engineering, Pune ${ }^{1,2,3}$ \\ Associate Professor, Bharati Vidyapeeth Deemed University, College of Engineering, Pune ${ }^{4}$
}

\begin{abstract}
Our mission is to design a system to manage the railway gate at the level crossing and switching mechanism for changing the track at railway station. The range of accidents associated with railway is increasing day by day, the above automations will reduce these accidents to a far extra volume. This project employs two pair of Infrared (IR) sensors, one pair of IR sensor is used to govern the railway gate and the other pair of IR sensor is used to switch the railway track according to the requirement .Track switching can be achieved by using the electromagnetic circuit or placing the motor arrangement. IR sensors are used to experience the appearance and departure of the train. As the entire system is automatic errors taking place due to manual operation are averted due to the fact the accuracy of automated operation is more than the manned operation. Our mission is advanced on an embedded system and the usage of a microcontroller as a controlling unit.
\end{abstract}

Keywords: Infrared (IR) sensor, microcontroller, Limit switch, Railway gate and track switching.

\section{INTRODUCTION}

Railways being the cheapest mode of transportation are preferred over all other means. When we undergo through each day newspapers, we get many news related to the railway injuries on at unmanned railway crossing that is generally occur because of the carelessness in manual operations or mistake of workers. We, on this undertaking has given you an answer of use of simple electronic components for the same work. The use of the identical principle as that for gate manipulation, we've developed an idea of switching the track which can reduce the overall time taken by the long route train. In a real performance railway prefers bidirectional wireless RF communication and simran locomotive equipment as a primary concern over this concept. This concept use as a subordinate in real automatic level crossing gate. In practical situation they prefer weighing sensor and the weight parameters is decided according to the weight of the train.

\section{WORKING}

In this project, we use IR transmitter receiver pair on each side of the gate. They are placed at some distance from the gate terminal .Distance between the gate terminal and sensor is decided by the maximum speed of the train. When train cuts first sensor, Green light convert into Red; a buzzer gets activated for 2 seconds and railway gate will closed with the rotation of 90 degree of first motor. When train cuts second sensor then a light signal again toggled from Red to Green; again buzzer gets activated for 2 Seconds and gates will open.

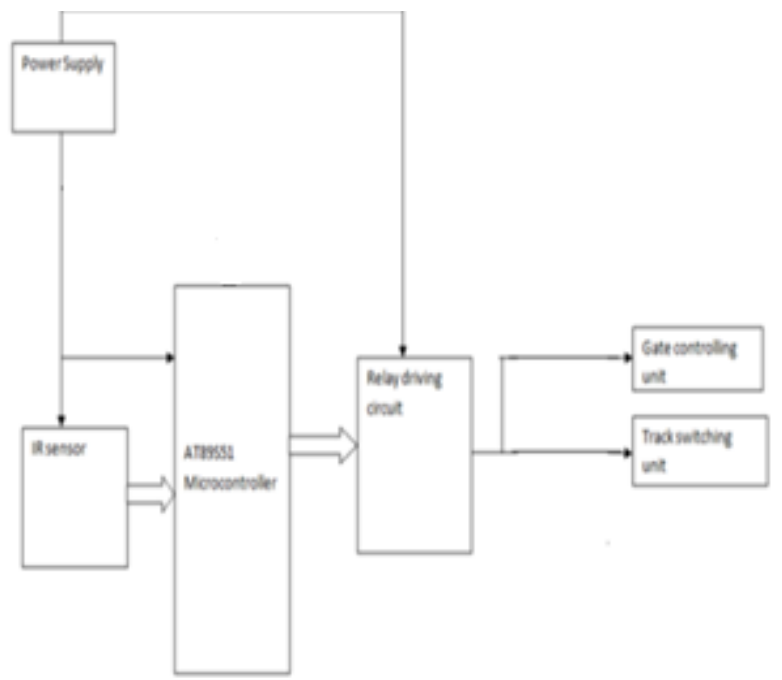

Fig.1 Block Diagram 
Two sensors are placed at the either sides of the junction where the track switches. If there's a train approaching from the other side, then another sensor placed along that direction gets activated and second motor switches track.The microcontroller is the controlling unit which controls the railway gate segment, track switching segment by means of a relay section. The movements achieved via the microcontroller rely upon the transition of strength from the IR sensor. IR sensors: The IR sensor section includes an IR transmitter and receiving segment, transmitter phase consists of an IR led with a contemporary proscribing resistor of $1 \mathrm{~K}$ ohms which constantly emits photons on the receiving unit.

Transmitter section consists of an IR led with a current limiting resistor of 1Kilo ohms which continuously emits photons on the receiving unit. IR receiver consist of photodiode which works on the concept of reverse characteristic.IR receiver receives the photons from the IR led and the sensor output convert into digital form with the help of $\operatorname{lm} 324$ comparator. $\operatorname{lm} 324$ output gives to the microcontroller.

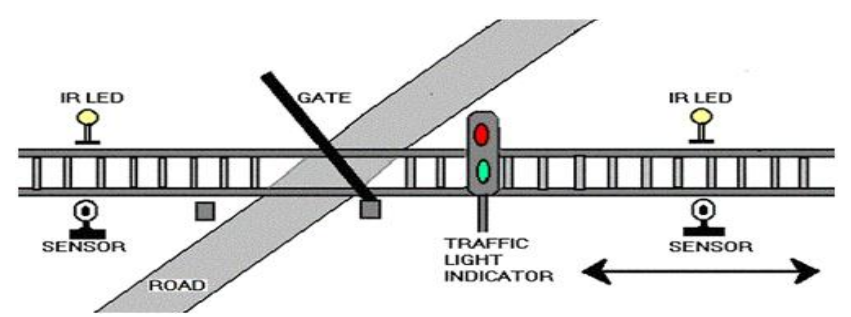

Fig.2 Gate Operation

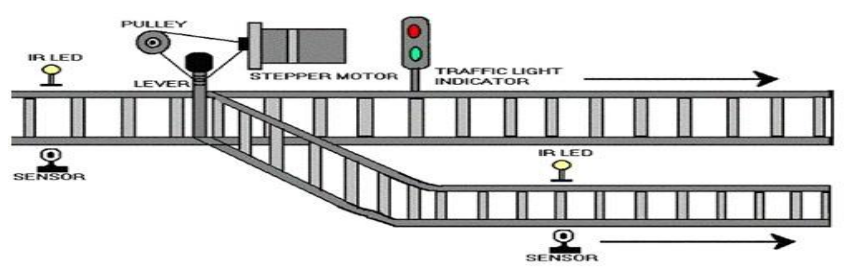

Fig.3Track switching

\section{A.7805 Voltage Regulator:}

7805 voltage regulator is used to convert the voltage from high to 5 volt value .It consist of three pins. Rectifier bridge also used with regulator to convert the ac voltage into pure dc form, two capacitors also used along with the regulator to eliminate the spikes of the input voltage. Above 9 volt we use heat sink to eliminate the heating effect.

\section{B. Microcontroller AT89S51}

The AT89S51 is a low-power, high-performance CMOS 8-bit microcomputer with 4K bytes of Flash programmable and erasable read only memory (PEROM). This is a heart of our project. Pin 18 and 19 is used to connect the crystal oscillator for timing application. It is a 40 pin controller. Sensors are connected from port 1.0 to port 1.5 and motor driver are connected from port 2.0 to port 2.3. Pin 40 used for the supply and pin 20 connected to the ground.

\section{Relay}

A relay is a device which is used to isolate the one circuit to another circuit electrically and link the circuit magnetically. This device used between electrical and electronic circuitry. With the help of this component, we can operate the small motor with $230 \mathrm{v}$ ac supply. A relay has two parts: input and output. Input has one operating coil which operate on $9 \mathrm{v}, 5 \mathrm{v}, 12 \mathrm{v}$. On the output there is lots of mechanical arrangement exist. There are three terminal exist on output side: $\mathrm{NO}, \mathrm{NC}$ and COM. At no input condition, $\mathrm{NC}$ is connected with the COM. When the voltage applied on operating coil, COM will be get shifted from NC to NO.
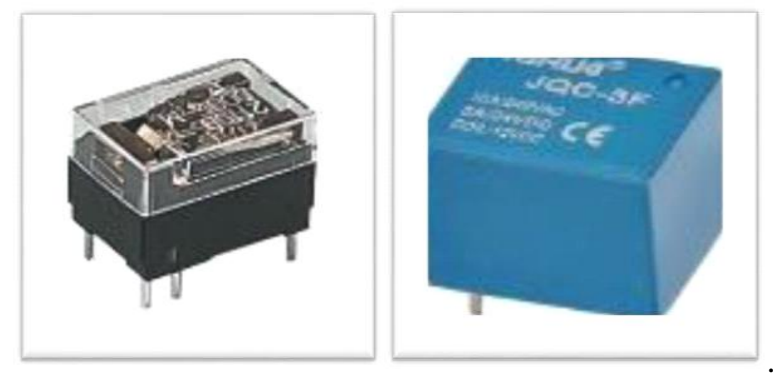


\section{L293DRIVER}

L293 driver consist of two h-bridge type circuit which is helpful to control the motor in both direction. That is why we can control the motor in both the direction.

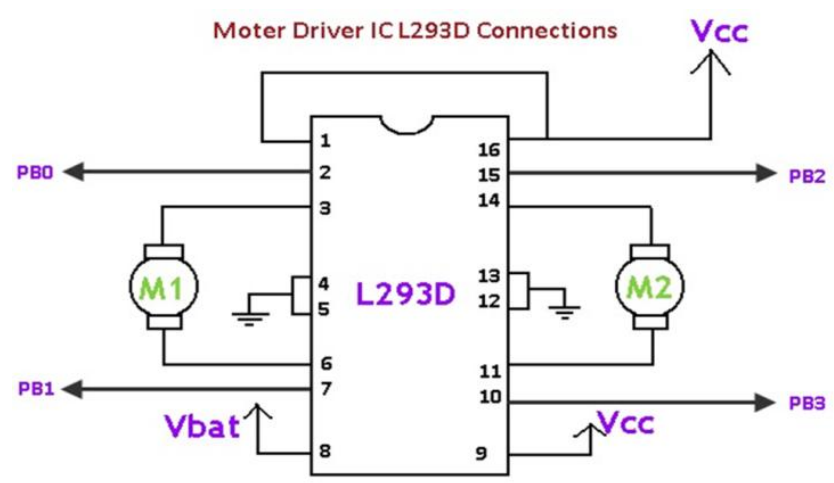

Pin 1 and pin 9 are enable pin which are used to enable the motor with h-bridge circuit. Pin 8 takes the particular voltage which is required to operate the motor. For driving the motor with left H-bridge you need to enable pin 1 to high. And for right H-Bridge you need to make the pin 9 to high. With this driver we can also connect four motor which will operate in one direction in whole operation.

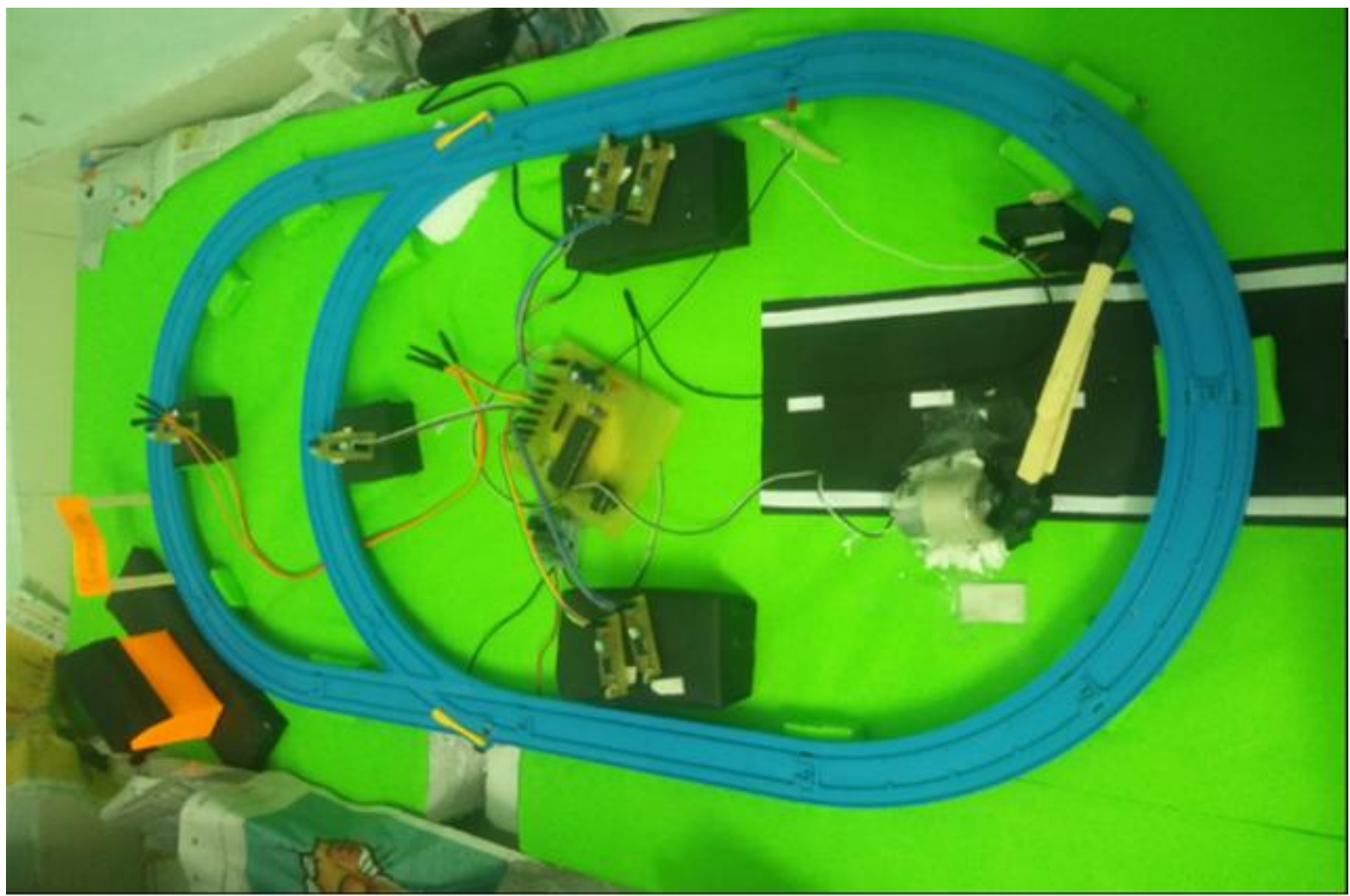

Final Representation of project

\section{E. Implementation of proposed system}

In our project we have used six sensor and each sensor output are high during the obstacle detection. Two sensor are placed on every side of the gate and distance between the two sensors are depend on the length of the train. This concept are used to differentiate between the train and other obstacle. Dc Motor is used to operate the gate. When the arrival sensors sense the train it will give signal to operate the motor in forward direction. Limit switch is used as a feedback circuit. Departure sensor sense the train and motor will rotate in reverse direction and gate will get open. For track switching, we use two sensor on both track. We are using the same concept in track switching. The delay angle of the track switching motor is less as compared to the gate motor. 


\section{F. FEEDBACK CIRCUIT}

Feedback circuit is used to give the signal to the train driver .It is used to prevent the accident which generally occur between train and other transportation due to the man error. This limit switch press by the plank of gate during closing operation and light will be toggled from red to green led.

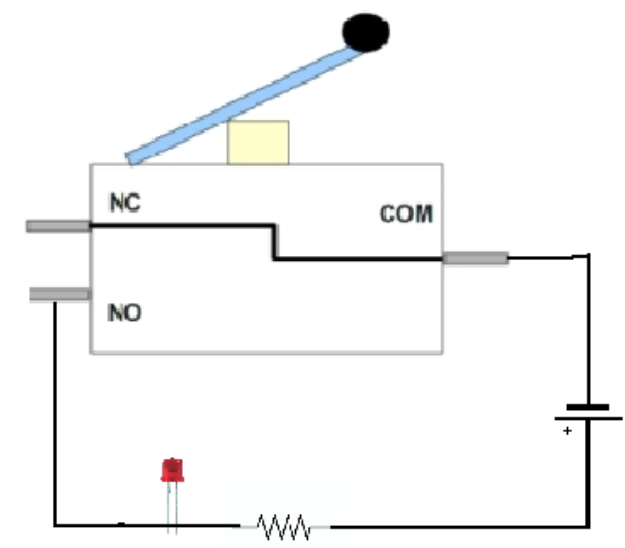

\section{G.ADVANTAGES AND LIMITATION}

In this proposed project, we have used a simple hardware and logic to make that operation effective. This concept is easy to control as compared to the navigation concept. Human intervention at level crossing has been totally removed and due to this many railway accident can be controlled. There are some limitation also associated with this project. Life cycle of IR sensor is very less and this sensor are also not strong enough to create a strong logic because IR cannot differentiate the metal and human. Wireless RF communication are more effective than electronics arrangement in terms of their speed and construction.

\section{H. SOFTWARE ELUCIDATION}

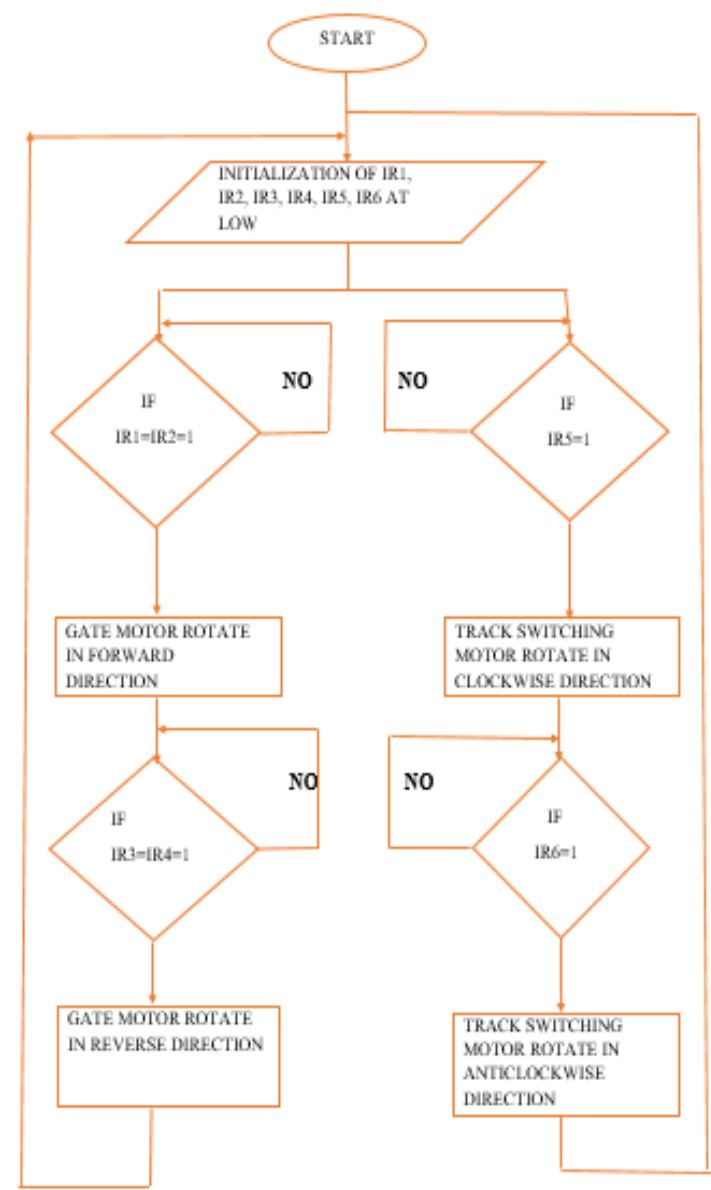


In this project we have used six sensor and two dc motor, one motor for gate control and other one for track switching. Initially the sensor output is low and when the train detected with sensor, output of the sensor will be converted into high. Keil compiler is used to write the system code and burner hardware is used to burn the program into microcontroller. If the IR1 and IR2 output is high then the motor will rotate in forward direction and when the ir3 and ir4 output is high then the motor will rotate in reverse direction and achieve its original position. Same logic is used for track switching.

\section{III .CONCLUSION}

The proposed assignment has created a lots of advantage in which it will reduce the accidents going on the railway stage crossing, it will boom the accuracy and reduce mistakes occurring due to guide operations. It'll reduce the collision of train and also reduce the overall time taken by the longer route which generally occur due to the human error. This concept makes the overall automation stronger in the railway section. This concept is used with the association of navigation concept. Sometime navigation does not work due to the environment problem then this comes into picture and with the association of this concept, objective of automation of railway gate has fully achieved. Solar energy are used as a supply at the operating location.

\section{REFERENCES}

[1] Ajay.V. Deshmukh, "Microcontrollers (Theory and Application)", Tata McGraw-Hill Publication, 2005. 7th International conference, Amman. 2010; 1-6.

[2]. V.K. Mehta, "Principles of Electronics", 11th edition, S Chand and Company, S.R.M University, 2009

[3] Peter Capper and C.T Elliott, "Infrared Emitters and Detectors", Kluwer Academic Publisher, 2001.

[4] Muhammad Ali Mazidi, Janice Gillispie Mazidi, Rolin.D. McKinlay, "The 8051 Microcontrollers and Embedded System", 2nd edition Pearson Education, 2008

[5] Krishna, Shashi Yadav and Nidhi, “Automatic Railway Gate Control Using Microcontroller", Oriental Journal of Computer Science \& Technology, Vol.6, No.4, page 435-440 December 2013.

[6] Ahmed Salih Mahdi, Al-Zuhairi, "Automatic Railway Gate and Crossing Control based Sensors \& Microcontroller", International Journal of Computer Trends and Technology (IJCTT) - volume 4 Issue 7-July 2013 